extending into the atrium in 77 of 1122 patients with renal cancer who underwent radical nephrectomy and complete tumor thrombectomy between 1970 and 2006 at 11 US and European institutions.

On the other hand, cardiac metastasis from a renal cell carcinoma without inferior vena cava extension is rare, and thus surgical treatment for this condition is also rare.

One study of 11,432 autopsies found only $266(2.33 \%)$ cardiac tumors, and almost all of them were metastases originating from the lung, bone marrow, lymph node, and kidneys $(3 / 266,1.1 \%) .^{2}$ Another study of 114 autopsies found metastatic cardiac tumors originating from melanoma, germ cell, leukemia, and the kidneys $(12 / 114,11 \%){ }^{3}$

Zustovich and colleagues ${ }^{4}$ reviewed 15 patients who were surgically treated for cardiac metastasis from renal cell carcinoma without inferior vena cava involvement. Their review considered the following as pathologic routes of metastatic spread: a venous hematogenous pathway mainly to the right side of the heart and a lymphatic pathway to the lymph nodes, lungs, pericardium, and left side of the heart. ${ }^{4}$ Metastasis to the right side seemed relatively more frequent, especially to the right ventricle. Among the 15 patients in that review, the right ventricle was involved in 10 of 11 with metastasis to the right side. ${ }^{4}$

We found only 1 report of a solitary right atrial metastasis from renal cell carcinoma without inferior vena cava involvement, and this symptomatic patient died shortly after surgery. ${ }^{5}$ Because right atrial tumors generally elicit few symptoms during the early phase, complete surgical resection is likely to be difficult. However, an asymptomatic right atrial tumor that was incidentally detected in our patient was metastasis that could be resected. This is the first report of a favorable outcome after complete surgical resection of a right atrial metastasis from renal cell carcinoma.

\section{CONCLUSIONS}

Progress in diagnostic imaging allows early diagnosis of not only symptomatic but also asymptomatic metastatic cardiac tumors. Surgery should be considered to improve the prognosis of patients in good condition with such malignancies and to prevent the occurrence of concomitant critical events.

\section{References}

1. Martínez-Salamanca JI, Huang WC, Millán I, Bertini R, Bianco FJ, Carballido JA, et al. Prognostic impact of the 2009 UICC/AJCC TNM Staging System for Renal Cell Carcinoma with Venous Extension. Eur Urol. 2011;59:120-7.

2. Butany J, Leong SW, Carmichael K, Komeda M. A 30-year analysis of cardiac neoplasms at autopsy. Can J Cardiol. 2005;21:675-80.

3. Roberts WC. Primary and secondary neoplasms of the heart. Am J Cardiol. 1997; 80:671-82.

4. Zustovich F, Gottardo F, De Zorzi L, Cecchetto A, Dal Bianco M, Mauro E, et al. Cardiac metastasis from renal cell carcinoma without inferior vena involvement: a review of the literature based on a case report. Two different patterns of spread? Int J Clin Oncol. 2008;13:271-4.

5. Pala S, Erkol A, Kahveci G. Massive right atrial metastasis from renal cell carcinoma without inferior vena cava involvement. Turk Kardiyol Dern Ars. 2009;37:358.

\title{
Transapical transcatheter aortic valve implantation and off-pump left internal thoracic artery-left anterior descending anastomosis: Back to the future?
}

\author{
Domenico Mazzitelli, MD, Nicolo Piazza, Sabine Bleiziffer, and Ruediger Lange, MD, PhD, \\ Munich, Germany
}

Coronary artery disease can be identified in up to $50 \%$ of patients undergoing transcatheter aortic valve implantation. The management of coronary artery disease in patients

From the Surgery Department, German Heart Center Munich, Munich, Germany. Disclosures: Authors have nothing to disclose with regard to commercial support.

Received for publication March 19, 2011; accepted for publication April 19, 2011; available ahead of print May 19, 2011.

Address for reprints: Domenico Mazzitelli, MD, Cardiovascular Surgery Department, German Heart Center Munich, Lazarettestr. 36, 80636, Munich, Germany (E-mail: mazzitelli@dhm.mhn.de).

J Thorac Cardiovasc Surg 2011;142:e144-6

0022-5223/\$36.00

Copyright (C) 2011 by The American Association for Thoracic Surgery

doi:10.1016/j.jtcvs.2011.04.023 undergoing transcatheter aortic valve implantation is currently a topic of debate. It is currently debated whether the presence of coronary artery disease or nonrevascularized myocardium is associated with an increased risk of adverse events in patients undergoing transcatheter aortic valve implantation.

We report a successful case of concomitant transapical aortic valve implantation and off-pump revascularization of the left anterior descending (LAD) artery via a left small thoracotomy. This procedure, which associates an older technique with a new one, can be an important hybrid strategy for the concomitant treatment of aortic stenosis and coronary artery disease. 


\section{CLINICAL SUMMARY}

An 81-year-old man with low-flow/low-gradient aortic stenosis presented with New York Heart Association class IV. Transesophageal echocardiogram revealed a calcified aortic valve with an effective orifice area of $0.6 \mathrm{~cm}^{2}$, mean transaortic valve gradient of $30 \mathrm{~mm} \mathrm{Hg}$, ejection fraction of $20 \%$, and pulmonary artery systolic hypertension (60 $\mathrm{mm} \mathrm{Hg}$ ). The aortic annulus measured $24 \mathrm{~mm}$. Coronary angiography demonstrated a $90 \%$ stenosis at the bifurcation of the LAD and first diagonal branch. Furthermore, the patient had a porcelain aorta identified by a multislice computed tomography scan. The patient presented with a history of persistent atrial fibrillation and moderate renal dysfunction. The patient's predicted 30-day mortality for a combined surgical aortic valve replacement and coronary artery bypass procedure was $30 \%$ by logistic European System for Cardiac Operative Risk Evaluation and 33\% by Society of Thoracic Surgeons' score.

Given the patient's porcelain aorta and low-flow/lowgradient aortic stenosis with severe left ventricular dysfunction (ejection fraction $20 \%$ ), the possibility of conventional surgery was rejected. Furthermore, percutaneous revascularization of the LAD diagonal bifurcation was considered too high risk by the referring cardiologist. After a multidisciplinary team discussion among the cardiac surgeons, cardiologists, and anesthesiologists, we opted to perform concomitant off-pump revascularization of the LAD with the left internal thoracic artery (LITA) and transapical aortic valve implantation using a 26-mm Edwards SAPIEN XT transcatheter heart valve (Edwards Lifesciences, Irvine, Calif).

The procedure was performed in a hybrid operating room under general anesthesia and double-lumen intubation. A cardiac surgeon and interventional cardiologist assisted with the procedure. Via a 6-cm left anterolateral thoracotomy, the chest was entered in the fifth intercostal space (Figure 1). This allowed a perfect exposition of the apex, but the LAD was too small at this level. Through the same skin incision, the fourth intercostal space was opened. The LAD had a diameter of approximately $2 \mathrm{~mm}$. The LITA was harvested under direct vision using a reusable retractor (Thoralift, Autosuture, US Surgical Corp, Norwalk, Conn). The LAD was stabilized with the Octopus system (Medtronic, Minneapolis, Minn), and the LITA-LAD anastomosis was completed using a running 7-0 Prolene (Ethicon, Inc, Somerville, NJ) suture. A flow of $36 \mathrm{~mL} / \mathrm{min}$ was measured with a transonic flowmeter.

Transapical aortic valve implantation was subsequently performed through the fifth intercostal space using a 26-mm Edwards SAPIEN XT prosthesis (Figure 2). The technique of transapical transcatheter aortic valve implantation has been described. ${ }^{1}$ Postimplantation angiography showed no aortic regurgitation. Graft patency was also

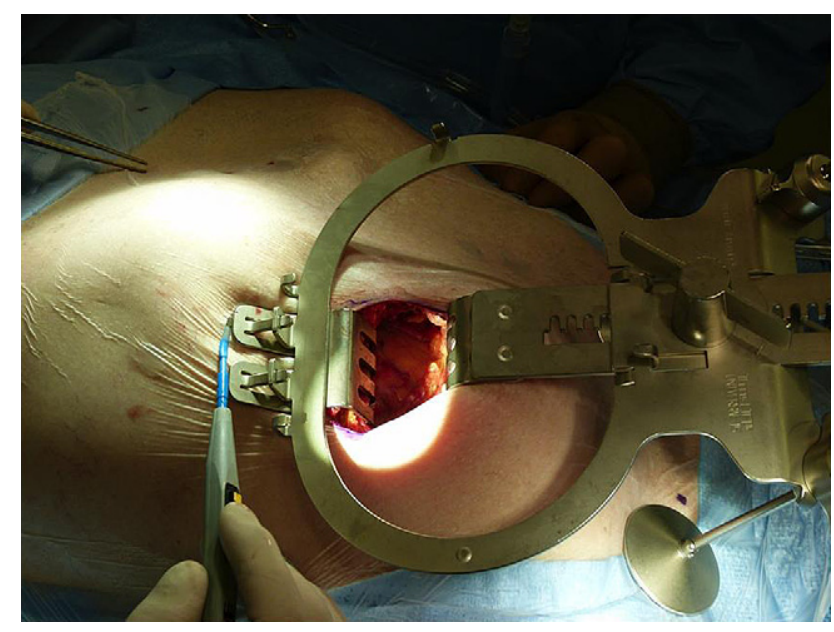

FIGURE 1. Anterolateral thoracotomy for off-pump coronary artery bypass and transapical aortic valve implantation.

confirmed by one selective injection of the LITA graft (Figure 2). No adverse events occurred postoperatively, and the patient was transferred to a rehabilitation facility on postoperative day 14 .

\section{DISCUSSION}

The present case demonstrates the feasibility of performing minimally invasive off-pump coronary artery bypass concomitant with transcatheter aortic valve implantation through the same left anterolateral thoracotomy site.

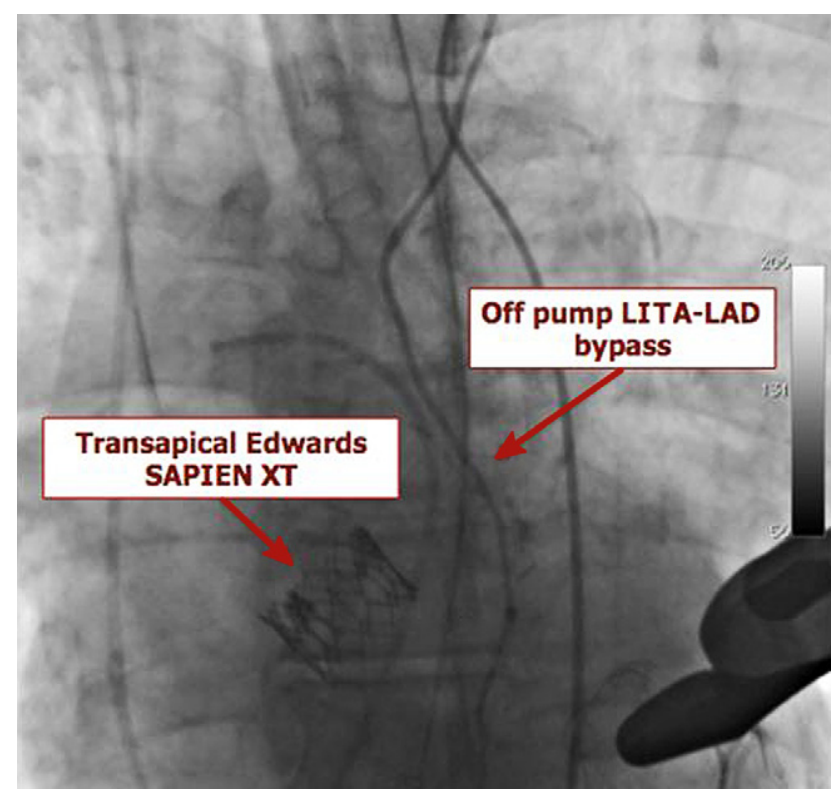

FIGURE 2. Coronary angiography showing a patent LITA-LAD bypass graft and Edwards SAPIEN XT valve in situ (Edwards Lifesciences, Irvine, Calif). LITA-LAD, Left internal thoracic artery-left anterior descending. 
Because of the patient's porcelain aorta and low-flow/ low-gradient severe aortic stenosis (ejection fraction $20 \%$ ), conventional surgical aortic valve replacement was denied. Furthermore, the referring cardiologist deemed percutaneous coronary intervention of the LAD diagonal bifurcation too high risk. Thus, through the same anterolateral thoracotomy, we opted to perform concomitant offpump coronary artery bypass of the LAD artery with the LITA and transapical aortic valve implantation using a 26-mm Edwards SAPIEN XT prosthesis. The feasibility of this approach has been described in only 2 other case reports. $^{2,3}$

It is currently debated whether the presence of coronary artery disease or non-revascularized myocardium is associated with an increased risk of adverse events in patients undergoing transcatheter aortic valve implantation. ${ }^{4,5}$

The described technique is minimally invasive, without the need of a heart-lung machine and provides the patient with a coronary artery bypass graft that is known to be durable. On the other hand, limited operator experience with off-pump coronary artery bypass surgery and difficulties with locating an adequate thoracotomy site for both bypass and valve implantation procedure can be potential challenges.

Minimally invasive off-pump coronary artery bypass surgery was popular in the 1990s. Although the results were excellent, the rapid growth of 1-vessel percutaneous coronary interventions contributed to a rapid decline of this technique. Although provocative, it is possible that once transcatheter aortic valve durability is established, a combined procedure as described may become an attractive treatment option for younger patients presenting with LAD coronary artery disease and severe aortic stenosis.

\section{CONCLUSIONS}

The fusion of transcatheter-based procedures and minimally invasive cardiothoracic surgery may provide an alternative in those instances when total transcatheter-based treatment is not possible or may even provide patients with a minimally invasive treatment associated with more durable results.

\section{References}

1. Walther T, Dewey T, Borger MA, et al. Transapical aortic valve implantation: step by step. Ann Thorac Surg. 2009;87:276-83.

2. Cheung A, Hon JK, Ye J, Webb J. Combined off-pump transapical transcatheter aortic valve implantation and minimally invasive direct coronary artery bypass. J Card Surg. 2010;25:660-2.

3. Mellert F, Breuer J, Probst C, Welz A, Schiller W. Combined transapical aortic valve replacement and minimally invasive direct coronary bypass graftinga new concept for selected high-risk patients. Heart Surg Forum. 2011;14: E61-3.

4. Dewey TM, Brown DL, Herbert MA, et al. Effect of concomitant coronary artery disease on procedural and late outcomes of transcatheter aortic valve implantation. Ann Thorac Surg. 2010;89:758-67.

5. Masson JB, Lee M, Boone RH, et al. Impact of coronary artery disease on outcomes after transcatheter aortic valve implantation. Catheter Cardiovasc Interv. 2010;76:165-73. 